\title{
Effects of Chronic Hookah Consumption on Aerobic Capacity, Resting and Sub-maximal Heart Rate in Men Who Are Trained and Untrained
}

Saeid Nasiri

Master of Exercise Physiology, Exercise Physiology, Ilam Branch, Islamic Azad University, Ilam, Iran.

Mahmoud Nikseresht

* Assistant Professor, Department of Exercise Physiology, Ilam Branch, Islamic Azad University, Ilam, Iran. (Corresponding Author)

Email: nikserasht@gmail.com

Abdolhossein Taheri Kalani

Assistant Professor, Department of Exercise Physiology, Ilam Branch, Islamic Azad University, llam, Iran.

Received: 3 March 2020

Accepted: 27 May 2020

Doi: 10.29252/ijhehp.8.2.187

\section{ABSTRACT}

Background and Objective: Hookah consumption is an underlying decline in lung function. However, data are limited on the physiological effects in young trained and untrained men. The purpose of this study was to investigate the effects of chronic hookah consumption on aerobic capacity (VO2max), resting and submaximal heart rate in men who are trained and untrained.

Materials and Methods: Forty-nine young men (18-34 years) were assigned into the following groups: a. trained-hookah $(n=11)$, b. untrained-hookah $(n=14), c$. trained $(n=12)$ and $d$. untrained $(n=12)$. The trained men had done at least three sessions (1-hour for each) of aerobic training a week during the past three years, while the untrained men had continued a sedentary lifestyle. Hookah smokers had smoked at least three times a week during the period. The VO2max, resting and submaximal heart rate indices were measured in all subjects.

Results: One-way analysis of variance showed that VO2max was significantly higher in trained group than the other groups, although no significant difference was observed in the other groups. Resting and submaximal heart rate were remarkably lower in the trained groups than in the untrained groups, but no significant difference was noted in the other groups.

Conclusion: The results of the present study indicated that hookah smoking has a negative effect on aerobic capacity in men who are trained; however, it seems that the effect of aerobic training is higher than the effect of hookah on resting and submaximal heart rate indices.

Keywords: Aerobic training, Heartbeat, Hookah, Maximum oxygen consumption Paper Type: Research Article.

Citation (Vancouver): Nasiri S, Nikseresht M, Taheri Kalani A. Effects of Chronic Hookah Consumption on Aerobic Capacity, Resting and Sub-maximal Heart Rate in Men Who Are Trained and Untrained. Iran J Health Educ Health Promot. Spring 2020;8(2): 187-194. [Persian]x

- Citation (APA): Nasiri S., Nikseresht M., Taheri Kalani A. Effects of Chronic Hookah Consumption on Aerobic Capacity, Resting and Sub-maximal Heart Rate in Men Who Are Trained and Untrained. (Summer 2020). Conc... . Iranian Journal of Health Education \& Health Promotion., 8(2), 187-194 . [Persian] 


\section{اثر طولانىمدت مصرف قليان بر ظرفيت هوازى، ضربان قلب زيربيشينه و استراحتى در مردان تمرينكرده و تمريننكرده}

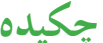

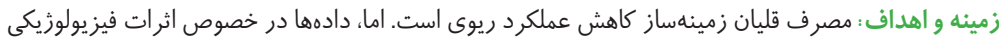

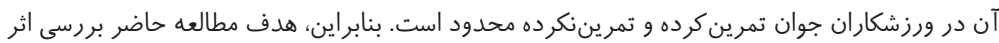

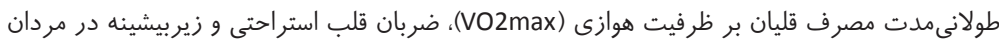

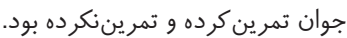

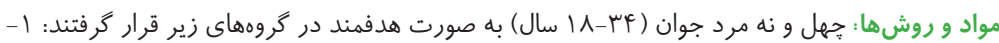

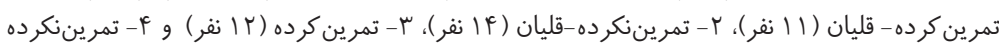

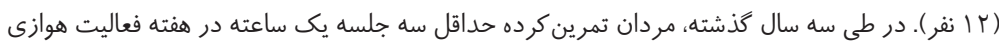

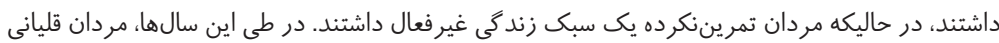

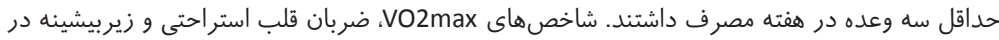

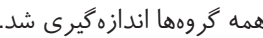

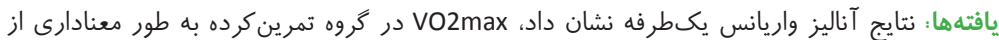

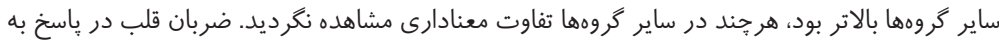

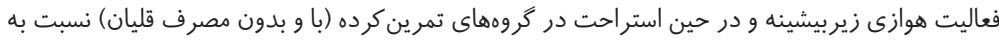

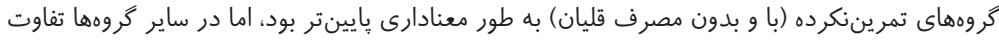

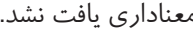

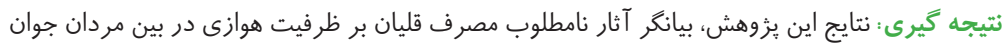

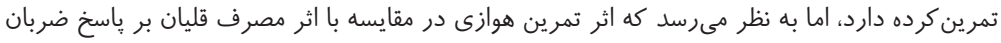

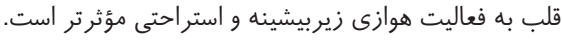

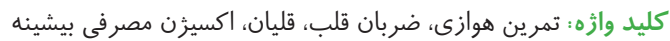

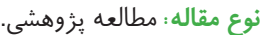

4 استناد (ونكوور): نصيرى س، نيكسرشت م، طاهرى كلانى ع. اثر طولانىمدت مصرف فر قليان برد

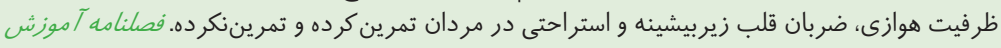

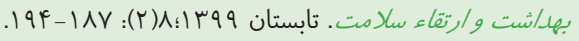

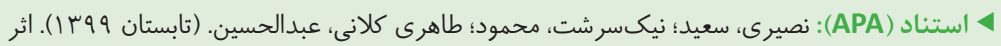

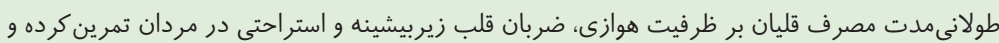

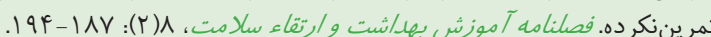

سعيد نصيرى

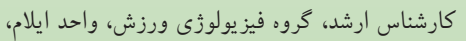
دانشعاء آزاد اسلامى، ايلام، ايران.

محمود نيك سرشت

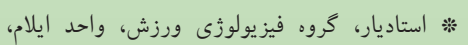

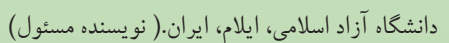
nikserasht@gmail.com

$$
\text { عبدالحسين طاهرى كلانى }
$$
استاديار، كروه فيز يولوزى ورزش، وادي، واحد ايلام، دانشكاه

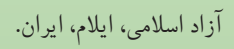

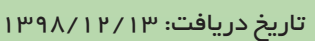

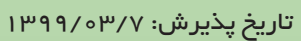


توسط سيستم اعصاب سمياتيك و پِاراسمياتيك اعمال مى گردد (9).

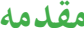
كزارش شده است كه مصرف سيكار موجب كاهش ظرفيت هوازى و بى هوازى، افزايش فعاليت سيستم اعصاب سمياتيك و كاهش سيستم اعصاب پاراسمياتيك در ورزشكاران زن در مقايسه با غيرسيكارىها شده است ( • ). مطالعهى ديكرى نشان داد كه ضربان قلب استر احتى مئى

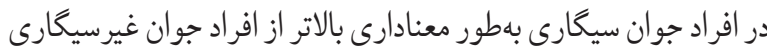
بود، ضربان قلب در ياسخ به فعاليت ورزشى فزاينده در افراد سيخارى در مقايسه با افراد غيرسيكارى با شيب كندترى افزايش يافت و حداكثر

ضربان قلب در اين افر اد بهطور معنادارى يايينتر بود (11).

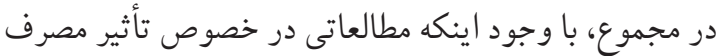

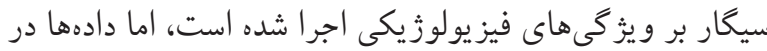

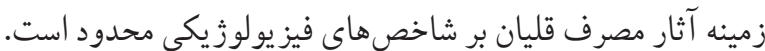
افزون بر اين، مشخص نيست كه مصرف درازمدت قليان ظرفيت

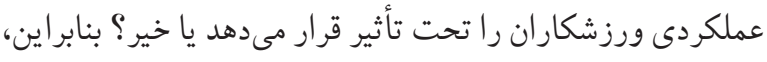

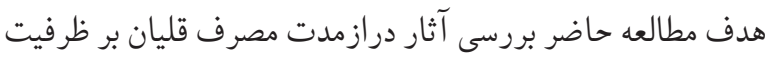
هوازى، ضربان قلب استر احتى و ضربان قلب در پِاسخ به فعاليت زيربيشينه در مردان تمر ين كرده و مردان تمرين نكرده مىباشد.

مو اد و روش ها روش يُوهش حاضر از نوع يس از وقوع است و طرح مورد استفاده

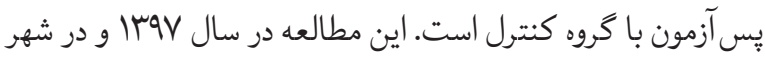

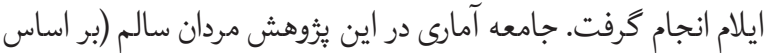

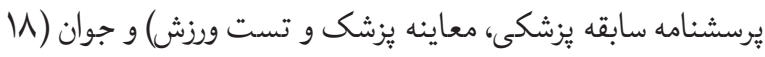

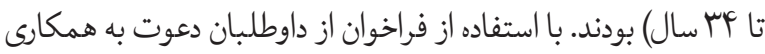

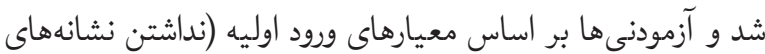

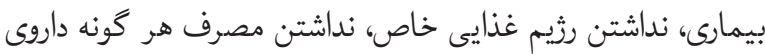

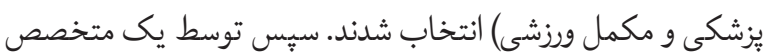

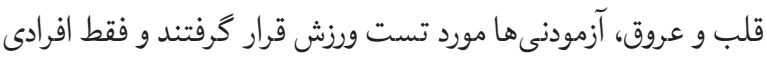
در مطالعه وارد شدند كه از نظر قلب-عروقى سالم بودند. با توجه به اهداف مطالعه، طبق معيارهاى اختصاصى زير در

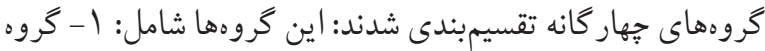

مصرف دخانيات يكى از دلايل اصلى مرگ و مير در جهان است. در

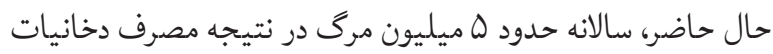

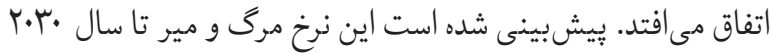

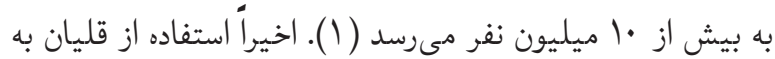
علت نبود قوانين منع مصرف در مجامع عمومى در بين نوجوانان

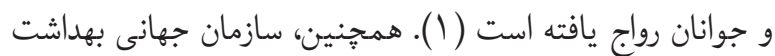

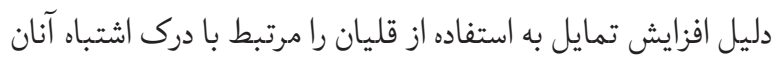
در بىضرر بودن مصرف قليان نسبت به ساير روشهاى مصرف تنباكو دانسته است (1). كزارش شده است كه لها درصد مردم

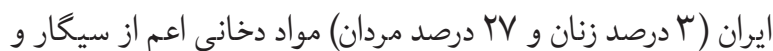

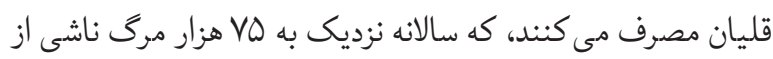
مصرف اين مواد رخ مىدهد (Y). در مجموع، شيوع مصرف قليان

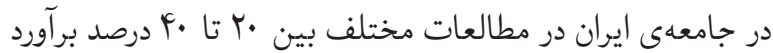
شده است كه در كروه سنى ه广 - צا سال رو به افزايش است (r).

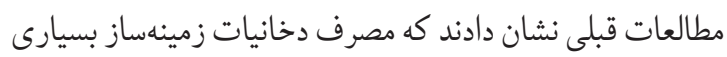

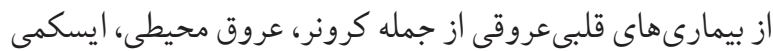

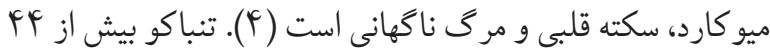

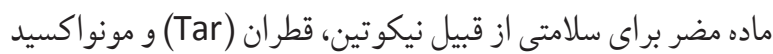

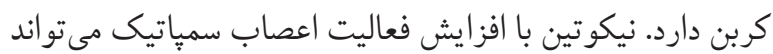
منجر به افزايش غلظت كاتكولامينها و در نهايت افزايش ضربان قلب و حجم ضربهاى شود (ه). قطران از سوختن تنباكو توليد شده و مىتواند منجر به افزايش مقاومت در مجارى تنفسى و يا كاهش

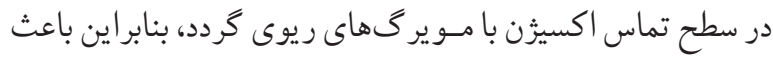

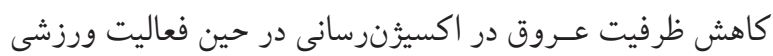

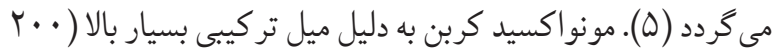

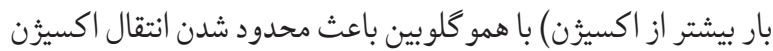

به عضلات شده و كاهش عملكرد ورزشى را به همراه دارد (9). يُزوهشكُان براى بررسى ارتباط بين مصرف دخانيات و بيمارى هاى قلبى عروقى اغلب از يك روش غير تهاجمى (تغييرات ضربان قلب) استفاده

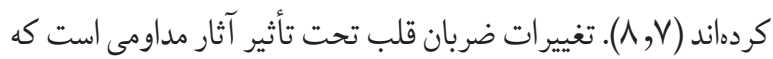


نوار گردان اقدام به بيادهروى تند نمودند و در اين وضعيت ضربان

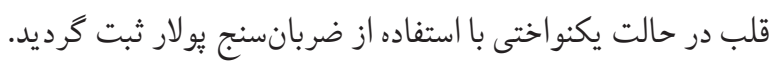

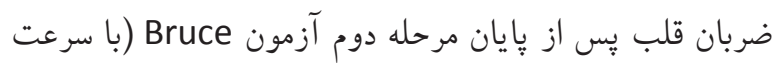

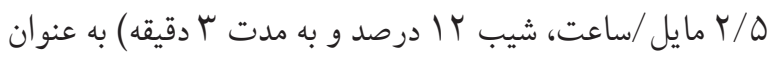

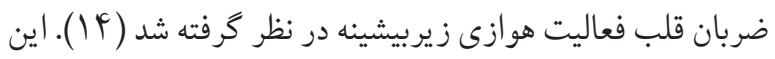

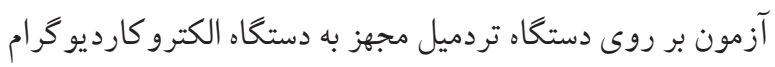
و زير نظر يك متخصص قلب اندازهخيرى شد.

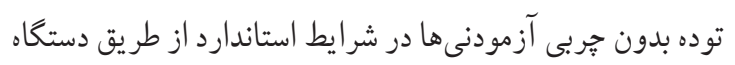

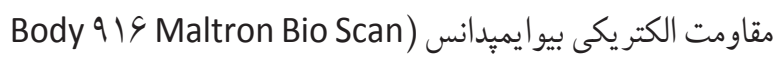
Composition Analyzer

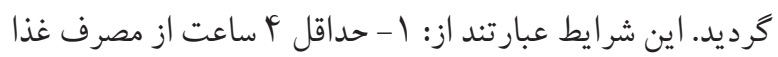

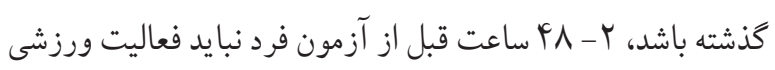

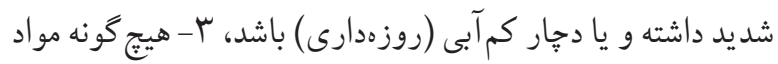

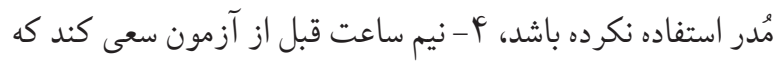

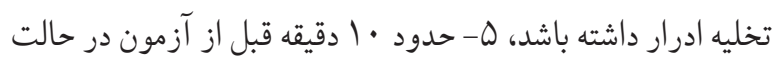

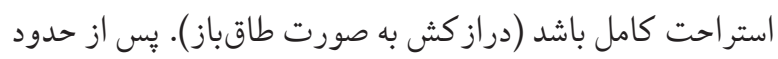

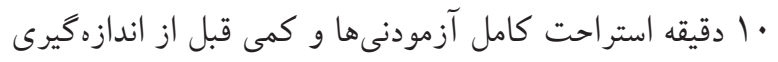

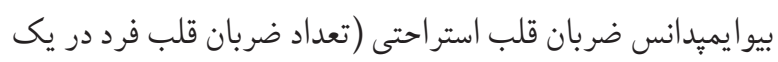

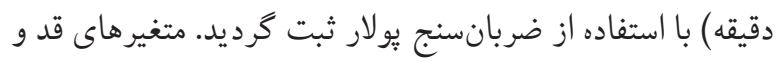
وزن با استفاده از قدسنج و ترازوى يزشكى Seca (ساخت آلمان)

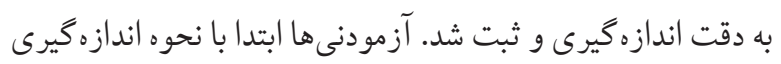
همه متغيرهاى فيز يولوزيكى آشنا شدند. همه اندازه خيرى ها بين أنداني ساعات ץ-ه بعدازظهر و توسط محقق صورت كرفت.

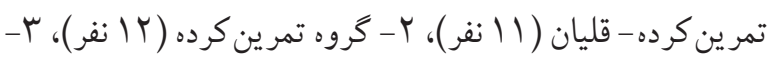

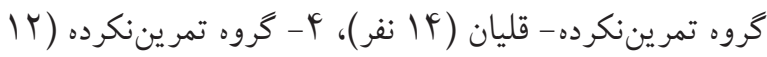
نفر). معيار اختصاصى براى كروههاى تمر ين كرده شامل دست كم

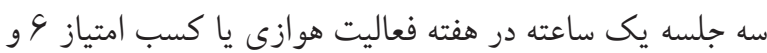

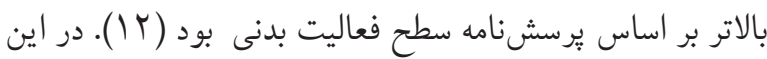

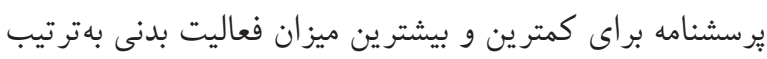
صفر و هفت امتياز در نظر كرفته شده است (جدول شماره ال). معيار

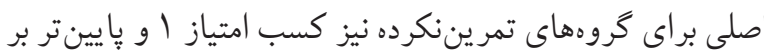

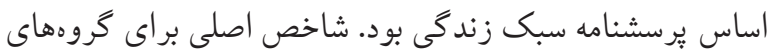

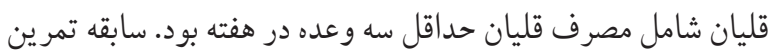
هوازى و مصرف قليان در گروههاى معرفى شده حداقل سه سال بود.

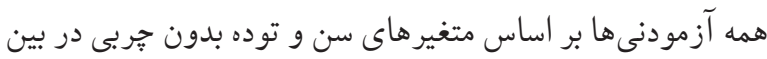

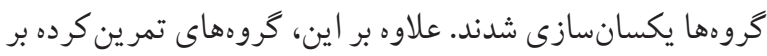
اساس سابقه تمرينى و گروههاى قليان بر اساس سابقه مصرف قليان

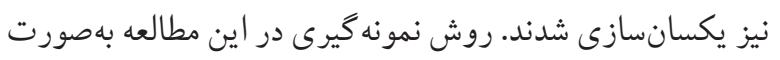

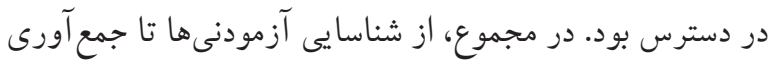

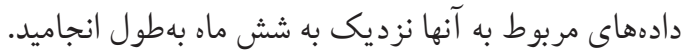

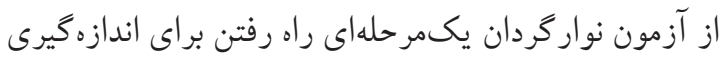

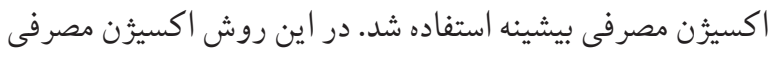

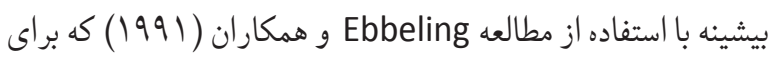

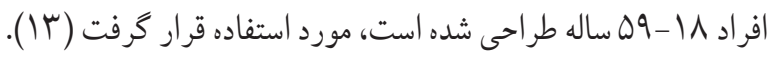

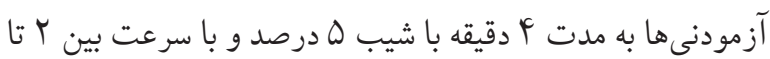

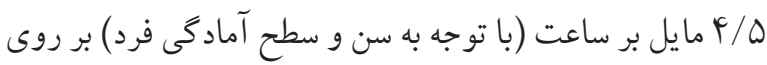
جدول ا : يرسشنامه سطح فعاليت بدنى

\begin{tabular}{|c|c|}
\hline 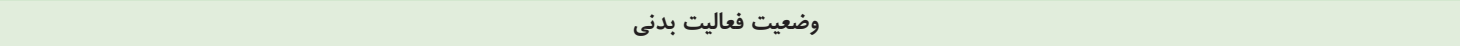 & امتياز \\
\hline اجتناب از يِاده روى يا فعاليت ورزشى (براى مثال: استفاده هميشكى از آسانسور، تا حد امكان استفاده از ماشين به جاى ييادهروى). & صفر \\
\hline 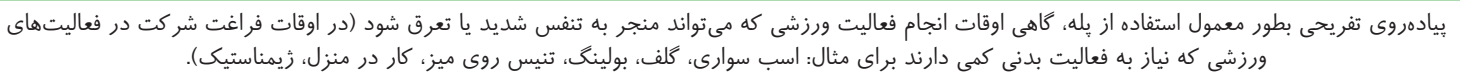 & 1 \\
\hline داشتن · ا تا ·و دقيقه فعاليت بدنى منظم در هفته & r \\
\hline 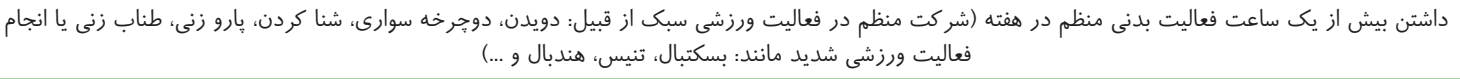 & r \\
\hline دويدن كمتر از يك مايل (1/ أ كيلومتر) در هفته يا فعاليت بدنى كمتر از ·ـ دقيقه در هفته & r \\
\hline دويدن ا تا ه مايل (و/ ا تا م كيلومتر) در هفته يا فعايت بدنى بين ·ץ تا ·ع دقيقه در هفته & $\Delta$ \\
\hline دويدن ه تا · ا مايل (^ تا و| كيلومتر) در هفته يا فعايت بدنى بين ا تا ب ساعت در هفته & 4 \\
\hline بيش از · إ مايل (1 ا كيلومتر) در هفته يا داشتن فعاليت بدنى بيش از ب ساعت در هفته & $\checkmark$ \\
\hline
\end{tabular}


ويثزى هاى دموكرافيك آزمودنىها در گروههاى جهارگانه در جدول

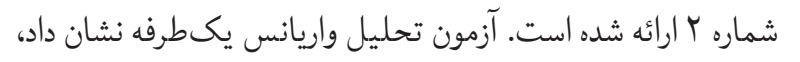
بين شاخصهاى سن، قد، توده بدن و توده بدون جربى بين جهار

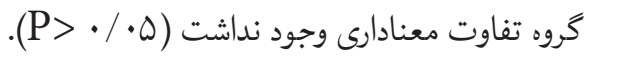

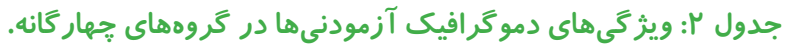

\begin{tabular}{|c|c|c|c|c|c|}
\hline \multicolumn{2}{|c|}{ آنواى يكطرفه } & \multicolumn{2}{|c|}{ شاخص مر كزى } & \multirow{2}{*}{ متغير ها } & \multirow{2}{*}{ كروهها } \\
\hline $\mathbf{P}$ & $\mathbf{F}$ & انحراف معيار & ميانگين & & \\
\hline \multirow{4}{*}{ 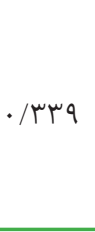 } & \multirow{4}{*}{$1 / \mid f$} & $r / 9$ & $r V / \Delta$ & \multirow{4}{*}{ سن (سال) } & تمرين كرده-قليان \\
\hline & & $r / \vee$ & $r F / F$ & & تمرين كرده \\
\hline & & $\Delta / \Delta$ & rN/S & & تمرين نكر ده-قليان \\
\hline & & $r / 9$ & $r s / f$ & & تمرين نكرده \\
\hline \multirow{4}{*}{$\cdot / M F F$} & \multirow{4}{*}{$1 / 10$} & $9 / 1$ & $\vee \Delta / \wedge$ & \multirow{4}{*}{ توده بدن (كيلوگرم) } & تمرين كرده-قليان \\
\hline & & $9 / 0$ & $V \Psi / \Delta$ & & تمرين كرده \\
\hline & & $0 / 4$ & $\wedge 1 / \wedge$ & & تمريننكر ده-قليان \\
\hline & & $1 \cdot / 4$ & $V F / q$ & & تمرين تكرده \\
\hline \multirow{4}{*}{$\cdot 1199$} & \multirow{4}{*}{$1 / 1 \cdot 1$} & $r / 9$ & $I V \Delta / \mathcal{F}$ & \multirow{4}{*}{ قد (سانتىمتر) } & تمرين كرده-قليان \\
\hline & & $s / V$ & $1 \wedge \cdot / \mu$ & & تمرين كرده \\
\hline & & $4 / 1$ & $I V V / \Lambda$ & & تمريننكر ده-قليان \\
\hline & & $0 / 1$ & $189 / 9$ & & 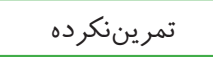 \\
\hline \multirow{4}{*}{. JVs } & \multirow{4}{*}{$\cdot /$ rAV } & $\mathrm{V} / \mu$ & sl/r & \multirow{4}{*}{ توده بدون جربى (كيلوگرم) } & تمرين كرده-قليان \\
\hline & & $4 / 1$ & $s F / F$ & & تمرين كرده \\
\hline & & $\Delta / \Lambda$ & $s \pi / \Delta$ & & تمرين نكر ده-قليان \\
\hline & & $s / \uparrow$ & $s \mu / 1$ & & تمرين تكرده \\
\hline
\end{tabular}

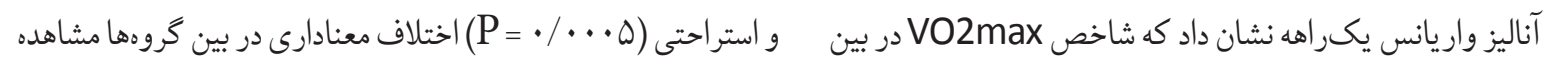

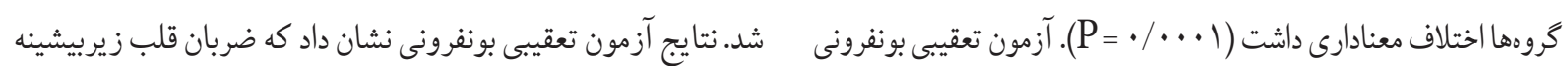

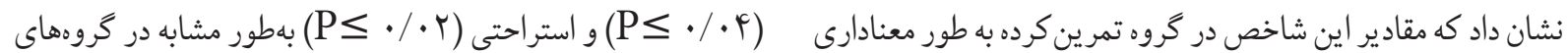

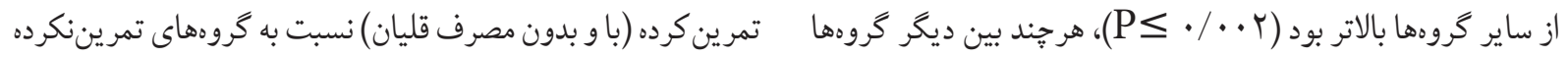

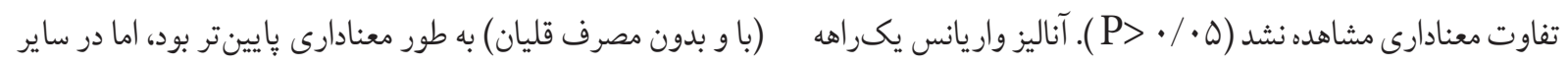

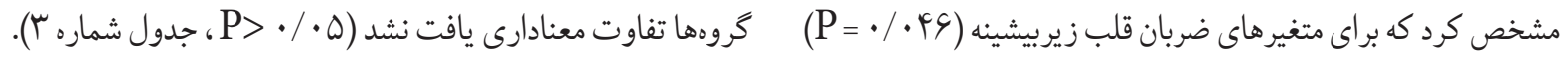


جدول "ّ: شاخصهاى ضربان قلب زير بيشينه و استراحتى در بين گروهها.

\begin{tabular}{|c|c|c|c|c|c|}
\hline \multicolumn{2}{|c|}{ آنواى يكر اهه } & \multicolumn{2}{|c|}{ شاخص مر كزى } & \multirow{2}{*}{ متغير ها } & \multirow{2}{*}{ كروهها } \\
\hline $\mathbf{P}$ & $\mathbf{F}$ & انحراف معيار & ميانكين & & \\
\hline \multirow{4}{*}{$g \cdot / . i s$} & \multirow{4}{*}{$r / 9 s 9$} & $\Lambda / \mu$ & $\mid r r / \Delta$ & \multirow{4}{*}{ ضربان قلب زيربيشينه (تعداد / } & تمرين كرده-قليان \\
\hline & & $V / \uparrow$ & $\mid r r / \Lambda$ & & تمرين كرده \\
\hline & & $1 r / 1$ & $1 r \Delta /{ }^{c}$ & & تمريننكر ده-قليان \\
\hline & & $9 / \mu$ & $\mid r v / f$ & & تمرين نكرده \\
\hline \multirow{4}{*}{$\S \cdot 1 \cdots \Delta$} & \multirow{4}{*}{$\wedge / \Lambda$} & $1 \cdot 14$ & $91 / 1$ & \multirow{4}{*}{ ضربان قلب استراحتى (تعداد / دقيقه) } & تمرينكرده-قليان \\
\hline & & $\Delta / \wedge$ & sm/q & & تمرين كرده \\
\hline & & $\mathrm{V} / \cdot$ & $\vee \Delta / \wedge$ & & تمريننكرده-قليان \\
\hline & & $\Delta / \Lambda$ & $\mathrm{V} / \cdot$ & & تمرين نكر ده \\
\hline \multirow{4}{*}{$¥ \cdot / \cdots 1$} & \multirow{4}{*}{$\mid \boldsymbol{f} / \boldsymbol{\mu}$. } & $\Delta / \mu$ & $\wedge \Delta / 1$ & \multirow{4}{*}{ 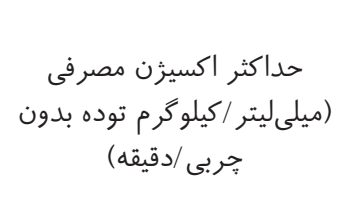 } & تمرينكرده-قليان \\
\hline & & $r / f$ & $9 r / 0$ & & تمرين كرده \\
\hline & & $F / 1$ & $\Lambda 1 / \mu$ & & تمرين نكر ده-قليان \\
\hline & & $r / \mu$ & $\Lambda \Delta / 9$ & & تمرين نكرده \\
\hline
\end{tabular}

خصوص اثر مصرف سيكار اطلاعات بيشترى موجود است. براى

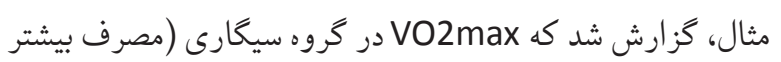

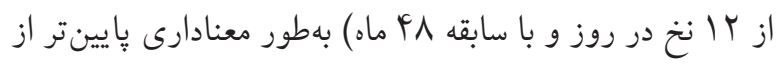
افراد غيرسيكارى بود ( • ())، كه با يافته مطالعه حاضر همسو است.

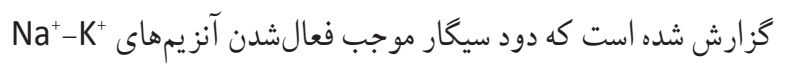

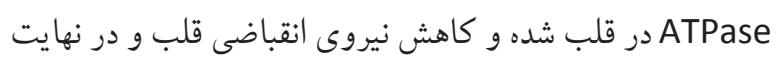

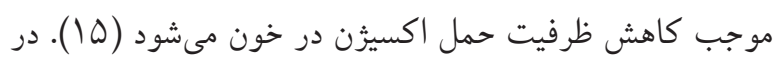

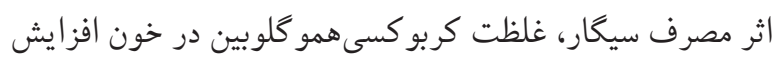
يافته و ميزان جدا شدن اكسيزن از همو كلوبين در سطح سلولى را كاهش مىدهد (91). افزون بر اين، ظرفيت حمل اكسيزن توسط

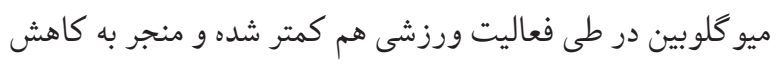

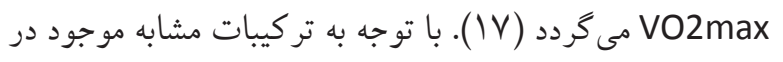

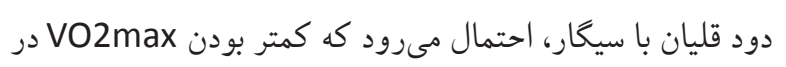
افراد مصرف كننده قليان به دلايل فوق باشد.

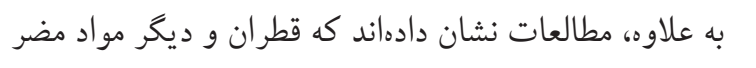

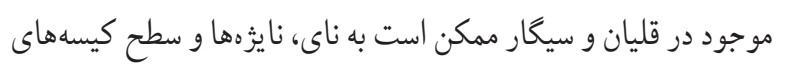

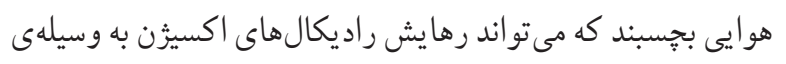
ماكروفازهاى كيسههاى هوايى و نوتروفيل كرانولوسيتى در خون
و: تفاوت معنادارى بين گروههاى تمرين كرده (با و بدون

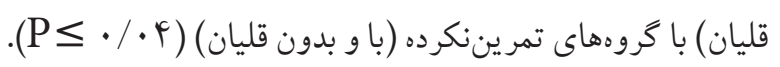
\: تفاوت معنادارى بين كروههاى تمرين كرده (با و بدون

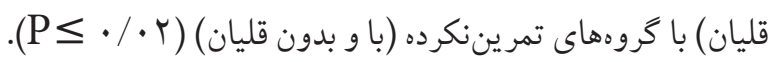

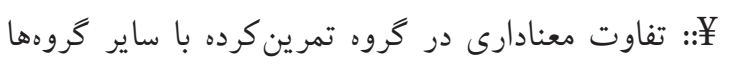
$(\mathrm{P} \leq \cdot / \cdot r)$

بحث مهمترين يافته مطالعه حاضر نشان داد كه شاخص VO2max در

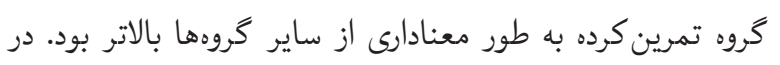

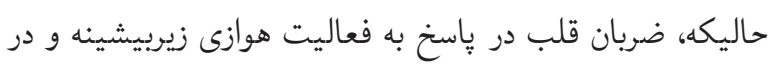
حين استراحت در گروههاى تمرين كرده (با و بدون مصرف قليان) نسبت به گروههاى تمرين نكرده (با و بدون مصرف قليان) به طور معنادارى پِايين تر بود. ڤايين تر بودن شاخص VO2max در مردان تمر ين كرده-قليان

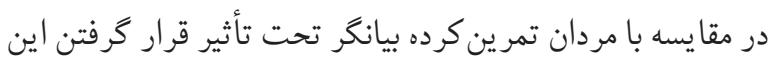
شاخص مهم قلبى-تنفسى با مصرف قليان است. يُزوهش ها در برد

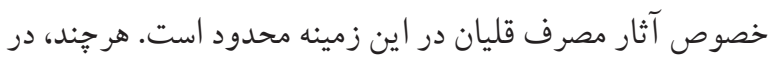


اكسيزن مصرفى) در يك فعاليت زيربيشينه در افراد سيگارى به ميزان ال درصد بالاتر از افراد غيرسيخارى بود ( • †). بالاتر بودن نسبت تبادل تنفسى و يا ضربان قلب در يك فعاليت ورزشى زيربيشينه نشانگر كارايى ضعيف فر آيند توليد انرزى در بدن است. نتيجه كيرى: با توجه به يافتهاى اين يزّوهش مىتوان كفت، مصرف درازمدت قليان آثار نامطلوبى بر عملكرد قلبى - تنفسى دارد و موجب كاهش VO2max در مردان جوان مىشود. اخر جه، ضربان قلب استراحتى و ضربان قلب زير بيشينه در مردان جوان سالم تحت تأثير مصرف قليان نگرفت. بر اساس نتايج به دست آمده به ورزشكاران جوان و ساير افراد جامعه توصيه مىشود كه مصرف قليان را به دليل آثار نامطلوب بر ظرفيت هوازى متوقف نمايند. تضاد منافع: سهم تمامى نويسندگان دراين مطالعه يكسان است وهيجßگ تشكر و قدردانى: اين مقاله حاصل از ياياننامه مقطع كارشناس ارشد رشته فيزيولوزى ورزشى در دانشگاه آزاد اسلامى واحد ايلام است. نو يسند كان مراتب تقدير خود را آزمودنى هاى شر كت كننده در مطالعه ابراز مىدارند.

\section{References}

1. Panahi R, Ramezankhani A, Tavousi M, HaeriMehrizi A, Osmani F, Niknami S. Studying and comparison of health literacy among smokers and non-smokers students in Shahid Beheshti University of Medical Sciences in 2016. Journal of Health Literacy. 2018;2(4):255-65. https://doi.org/10.22038/jhl.2018.10881

2. kaveh MH, Jafari2 A, Keshavarzi S, Momenabadi V, Taheri $M$, Dehbozorgi $F$, et al. Evaluation of explanation of the BASNEF model on smoking waterpipe among the students one of the medical universities located in the south of Iran. Iranian Journal of Health Education and Health Promotion. 2019;7(4):312-22. https://doi.org/10.29252/ijhehp.7.4.312

3. Jahanpour F, Vahedparast $H$, Ravanipour M, Azodi P. The trend of hookah use among adolescents and youth: $A$ qualitative study. Journal of Qualitative Research in Health Sciences. 2015;3(4):340-8.

4. Kharaghani K, Habibpour ghatabi K, Barandeghi B. The
را افزايش دهد (1) (1). در نتيجه، به دليل جسببندگى لكوسيتى و سلولهاى اندو تليال، يُاسخهاى التهابى گسترش يافته و سرانجام موجب تخريب بافت ريوى و بدكارى آن شود (X). به علاوه، نيكوتين (از ديگر مواد موجود در قليان) مىتواند سبب بالارفتن فشار خون، ضربان قلب قوى، أفت عملكرد يميازى قلب و افزايش اكسيزن مصرفى بدن شدهو در نتيجه ظرفيت هوازى را كاهش دهد (1) 19 (1). از آنجايى كه آزمودنىهاى كروههاى مصرف كننده قليان در درازمدت با دود قليان مو اجه بودهاند، ممكن است كاهش VO2max آن باشد. گرجه براى اظهار نظر صريح، به مطالعات كنترل شدهى بيشترى در اين زمينه نياز است. يايينتر بودن ضربان قلب استراحتى و در ياسخ به فعاليت زيربيشينه در گروههاى تمرين كرده (با و بدون مصرف قليان) نسبت به گروههاى تمرين نكرده (با و بدون مصرف قليان) يافتهى ديخر يُخوهش حاضر است كه بيانكر اهميت تمر ين هوازى در مقايسه با مصرف قليان است. بهعبارت ديگر، مىتوان گفت كه اثر تمرين هوازى بر تنظيم و فعاليت سيستم عصبى خودكار قوىتر از اثر مصرف درازمدت قليان است. در حمايت از اين يافته كزارش شده است كه نسبت تبادل تنفسى (حجم دى اكسيد كربن توليدى /حجم

Role of Tehranian Citizens' Participation in Realization «Tobacco-Free Tehran Programme». Iranian Journal of Health Education and Health Promotion. 2020;8(1):82-92. https://doi.org/10.29252/ijhehp.8.1.82

5. Colberg SR, Casazza GA, Horning MA, Brooks GA. Increased dependence on blood glucose in smokers during rest and sustained exercise. Journal of applied physiology (Bethesda, Md : 1985). 1994;76(1):26-32. https://doi.org/10.1152/jappl.1994.76.1.26 PMid:8175515

6. King CE, Dodd SL, Cain SM. $\mathrm{O} 2$ delivery to contracting muscle during hypoxic or CO hypoxia. Journal of applied physiology (Bethesda, Md : 1985). 1987;63(2):726-32. https://doi.org/10.1152/jappl.1987.63.2.726 PMid:3654434

7. Barutcu I, Esen AM, Kaya D, Turkmen M, Karakaya O, Melek $\mathrm{M}$, et al. Cigarette smoking and heart rate variability: dynamic influence of parasympathetic and sympathetic 
maneuvers. Annals of noninvasive electrocardiology : the official journal of the International Society for Holter and Noninvasive Electrocardiology, Inc. 2005;10(3):324-9. https://doi.org/10.1111/j.1542-474X.2005.00636.x PMid:16029383 PMCid:PMC6932108

8. Cagirci G, Cay S, Karakurt O, Eryasar N, Kaya V, Canga A, et al. Influence of heavy cigarette smoking on heart rate variability and heart rate turbulence parameters. Annals of noninvasive electrocardiology : the official journal of the International Society for Holter and Noninvasive Electrocardiology, Inc. 2009;14(4):327-32. https://doi.org/10.1111/j.1542-474X.2009.00321.x PMid:19804508 PMCid:PMC6931945

9. Bergh U, Ekblom B, Astrand PO. Maximal oxygen uptake "classical" versus "contemporary" viewpoints. Medicine and science in sports and exercise. 2000;32(1):85-8. https://doi.org/10.1097/00005768-200001000-00013 PMid:10647533

10. Lee $C L$, Chang WD. The effects of cigarette smoking on aerobic and anaerobic capacity and heart rate variability among female university students. International journal of women's health. 2013;5:667-79. htt p s: / / d o i.org / 10.2147 / I W H.S49220 PMid:24204174 PMCid:PMC3804543

11. Papathanasiou G, Georgakopoulos D, Papageorgiou E, Zerva E, Michalis L, Kalfakakou V, et al. Effects of smoking on heart rate at rest and during exercise, and on heart rate recovery, in young adults. Hellenic journal of cardiology : HJC = Hellenike kardiologike epitheorese. 2013;54(3):16877.

12. Jackson AS, Blair SN, Mahar MT, Wier LT, Ross RM, Stuteville JE. Prediction of functional aerobic capacity without exercise testing. Medicine and science in sports and exercise. 1990;22(6):863-70. https://doi.org/10.1249/00005768-199012000-00021 PMid:2287267

13. Ebbeling CB, Ward A, Puleo EM, Widrick J, Rippe JM. Development of a single-stage submaximal treadmill walking test. Medicine and science in sports and exercise. 1991;23(8):966-73. https://doi.org/10.1249/00005768-199108000-00014 PMid:1956273
14. Bruce RA, Kusumi F, Hosmer D. Maximal oxygen intake and nomographic assessment of functional aerobic impairment in cardiovascular disease. American heart journal. 1973;85(4):546-62. https://doi.org/10.1016/0002-8703(73)90502-4

15. Miura H, Toyama K, Pratt PF, Gutterman DD. Cigarette smoking impairs $\mathrm{Na+-K+-ATPase}$ activity in the human coronary microcirculation. American journal of physiology Heart and circulatory physiology. 2011;300(1):H109-17. https://doi.org/10.1152/ajpheart.00237.2010 PMid:21076023 PMCid:PMC3023254

16. Rietbrock N, KunkelS, Worner W, Eyer P. Oxygen-dissociation kinetics in the blood of smokers and non-smokers: interaction between oxygen and carbon monoxide at the hemoglobin molecule. Naunyn-Schmiedeberg's archives of pharmacology. 1992;345(1):123-8. h tt p s: / / d o i . org / 10.1007 / B F 00175479 PMid: 1538790

17. McDonough P, Moffatt RJ. Smoking-induced elevations in bloodcarboxyhaemoglobinlevels. Effectonmaximaloxygen uptake.Sportsmedicine(Auckland, NZ).1999;27(5):275-83. https://doi.org/10.2165/00007256-199927050-00001 PMid:10368876

18. He BM, Zhao SP, Peng ZY. Effects of cigarette smoking on HDL quantity and function: implications for atherosclerosis. Journal of cellular biochemistry. 2013;114(11):2431-6. h tt p s : / / d o i . org / $10.1002 /$ j c b. 24581 PMid:23852759

19. Hirooka N, Kadowaki T, Sekikawa A, Ueshima H, ChooJ, Miura $\mathrm{K}$, etal.Influence of cigarettesmoking oncoronaryarteryand aortic calcium among random samples from populations of middle-aged Japanese and Korean men. Journal of epidemiology and community health. 2013;67(2):119-24. https://doi.org/10.1136/jech-2011-200964 PMid:22844083 PMCid:PMC3521870

20. Kobayashi Y, Takeuchi T, Hosoi T, Loeppky JA. Effects of habitual smoking on cardiorespiratory responses to submaximal exercise. Journal of physiological anthropology and applied human science. 2004;23(5):163-9. h tt p s://doi .org/10.2114/jpa.23.163 PMid:15472461 